J. Transl. Med. Res 2016;21(1):69-73

\title{
Occupational Asthma of an Office Worker
}

\author{
Agripina Rașcu ${ }^{1,2}$, Ovidiu Ene ${ }^{3}$, Marina Oțelea ${ }^{3}$
}

Corresponding author:

Marina Oțelea, M.D.

Pathophysiology Department,

MateiBals Institute of Infectious

Diseases, Dr Grozovicist 1 ,

Bucharest, sector 2, 021105

E-mail:dr.marinaotelea@gmail.com

\author{
"'Carol Davila", University of Medicine and Pharmacy, Clinical Department 5, Bucharest, \\ Romania \\ ${ }^{2}$ Clinic of Occupational Diseases, Colentina University Hospital, Bucharest \\ ${ }^{3}$ Occupational health Department, Sanador Hospital, Bucharest, Romania \\ "'Carol Davila", University of Medicine and Pharmacy, Clinical Department 2, Bucharest, \\ Romania
}

\section{ABSTRACT}

Diagnosis of occupational asthma is always a challenge, particularly in a white collar setting, as it is a widespread belief that occupational respiratory diseases, including asthma, are associated only with industrial exposure. A detailed occupational history, a comprehensive workplace assessment and a proof of the relation between asthma attack and the presence of a risk factor in the workplace environment are the key factors for diagnosis. Early diagnosis of occupational asthma has a major positive influence on improving both evolution and prognosis. However, due to the reluctance of the patients to discuss health issues with coworkers, managers, occupational and family doctors, and to the difficulties in demonstrating that an occupational risk factor is the trigger of the asthma attack, the diagnosis is often delayed. We are reporting for the first time in Romania an occupational asthma in a bank desk officer that has been diagnosed after several years of work related symptoms by using the peakflowmetry measurement, a recently accepted demonstration of the occupational etiology of asthma. The peakflowmetry monitoring result, the workplace analysis and the presence of respiratory symptoms of the co-workers were fully conclusive in supporting the diagnosis of occupational asthma.

Key words: occupational asthma, office worker, peakflowmetry

\section{INTRODUCTION}

Occupational asthma is one of the most frequent adult onset asthma, with a prevalence of $10 \%$ in the adult population with asthma $(1,2,3)$. It is also the most frequent occupational respiratory disease in many developed countries (4, 5 ) and has an increasing incidence in developing countries.

The respiratory symptoms are caused or exacerbated by inhalation of allergenic or irritative substances from the working environment. The minimum attributable risk to work exposure is 6\%, (6) but occupations like bakers, farmers or laboratory animal workers, healthcare workers, painters and cleaners, plastic and rubber workers, are at a greater risk for developing asthma (7). The occupa- 
tions generating asthma in developed countries are more and more related to previously considered clean environments; for example, in Canada, the most frequent claims for work related asthma compensation were from education, services and healthcare sectors. (8) Establishing the occupational diagnosis is not always easy, as the trigger factor from the work environment might be difficult to identify. The first and mandatory step is always the occupational anamnesis.

\section{CASE REPORT}

We will present a female patient, 42 years old, non-smoker, overweight $(\mathrm{BMI}=27)$. She was an economist by training, but at the time of diagnosis, she worked as sales manager in a bank. She has been working in this bank for 10 years but in the last 2 years she changed her office, moving from the ground floor to the semi-basement of the building. She shared the office space with other 3 colleagues. In December 2014 she had an acute upper ways infection, with rhinorrhea and irritative cough. During the convalescence, while rhinorrhea and cough were reduced, but not completely disappeared, she had an episode of respiratory failure with severe dyspnea and cyanosis. She was transported by ambulance to the district emergency department where she has been admitted and treated with oxygen, systemic corticosteroids and bronchodilators (theophylline), antibiotics (cephalosporin). She had a good evolution and was discharged with diagnosis of acute interstitial pneumonia and respiratory failure. After the 14 days of sick leave, she came back to work in good condition, without any symptoms. After 2 days, her cough was back, with spastic exacerbations; in one week, the cough was almost permanent. The family doctor referred her to an endoscopy, in order to exclude gastro-esophageal reflux disease. The result was negative. In the $10^{\text {th }}$ day after coming back to work, she had a severe dyspnea and was admitted again in the emergency service. With systemic corticosteroids and bronchodilators, the symptoms were cleared. She was referred to the local pulmonologist, who raised the suspicion of asthma. Although spirometry values were normal, the patient received inhaled corticosteroids, leukotriene inhibitors, antihistamines and $\beta$-agonists for asthma crisis. Despite the anti-asthmatic therapy, symptoms were not controlled. Cough was permanent, dyspnea was more and more frequent and intense. Initially, the attacks started after a couple of hours from the beginning of work, but afterwards she had asthma attacks at home as well. The patient was admitted in the Clinic of Occupational Diseases on March 2015. The occupational anamnesis gave little information about presumed risk factors, as she was an office worker. However, the fact that 2 of her colleagues had symptoms of rhinitis and one of them had even an episode of irritative cough was found significant. The irritative cough episode of her coworker was solved without any medical assistance. Clinical examination was normal. Spirometry after $72 \mathrm{~h}$ of medication withdraw showed normal normal - forced expiratory volume in 1 second - FEV1 (82\%) values and a reduction of maximum expiratory flow when $50 \%$ forced expiratory vital capacity has been exhaled MEF 50 (58\%). The bronchodilator test was positive: (FEV1 increased with 31\%, and MEF 50 with 46\%), showing a high bronchial hyperreactivity. Prick tests to common allergens were not performed, as the patient had been under histamines for a long period. Taken into consideration the symptoms onset after 2 years of changing the work environment, the lack of response to medication and the symptoms of her colleagues, we decided for the Burge monitoring with computer assisted data interpretation as diagnostic test. Burge monitoring refers to serial measurements of the peak expiratory flow (PEF) for 2 weeks when patient is out of work compared with other 2 weeks when the patient is in his current job environment. It doesn't show the factor causing the asthma attack but it is a proof for the link between the work environment and asthma symptoms. The results from our patient are presented in fig. 1. By performing this test, we have been able to demonstrate a significant reduction in PEF during her working periods and a significant improvement while being outside of work. This test confirmed the existing asthma trigger in the work environment and could confirm the occupational asthma diagnosis.

In terms of treatment, beside the asthma medication, we recommended the patient to continue her work, but in another working environment. Fortunately, this recommendation has been implemented by her employer by refurbishing the office. The clinical evolution improved very much. By improving the air quality of the working environment, the respiratory symptoms of her colleagues also improved.

\section{DISCUSSIONS}

Although relatively frequent, the diagnosis of occupational asthma is not always easy to determine 


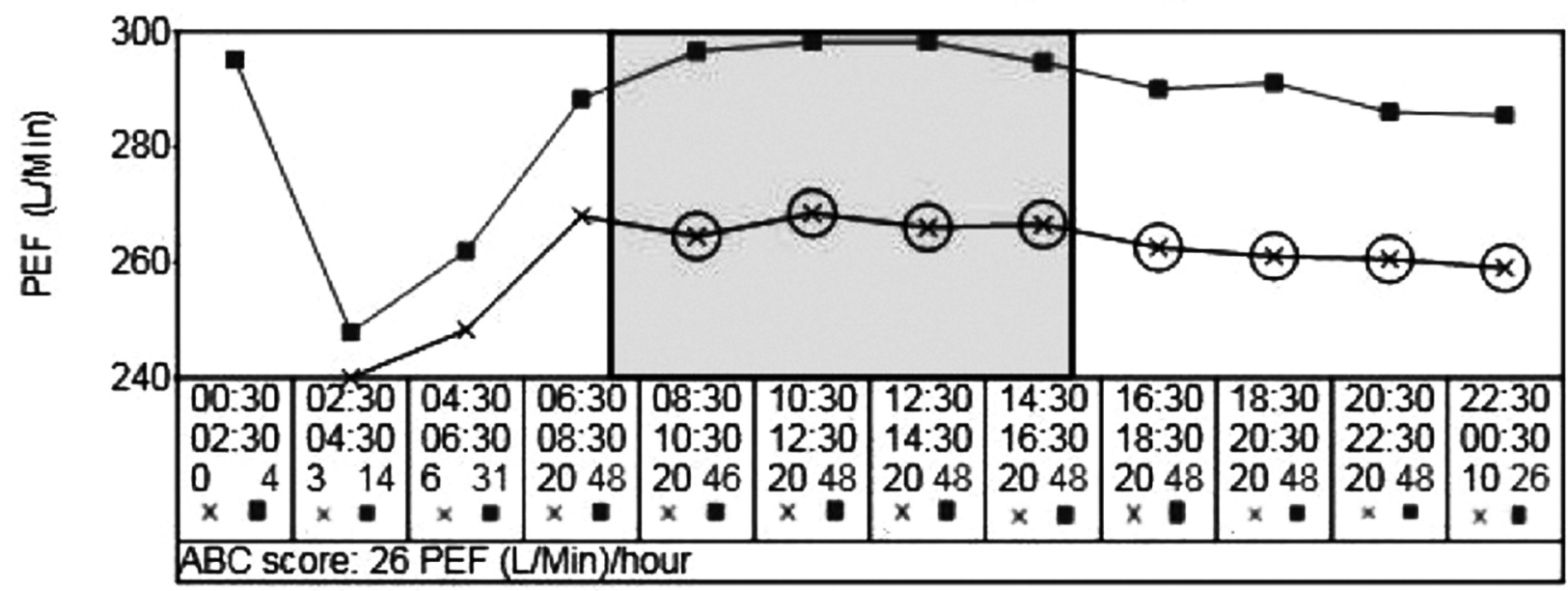

Time of Day, Number of Readings

(Day Shift x) (Rest $\cdot$ )

Average Hour from Waking for Rest and Day Shift days

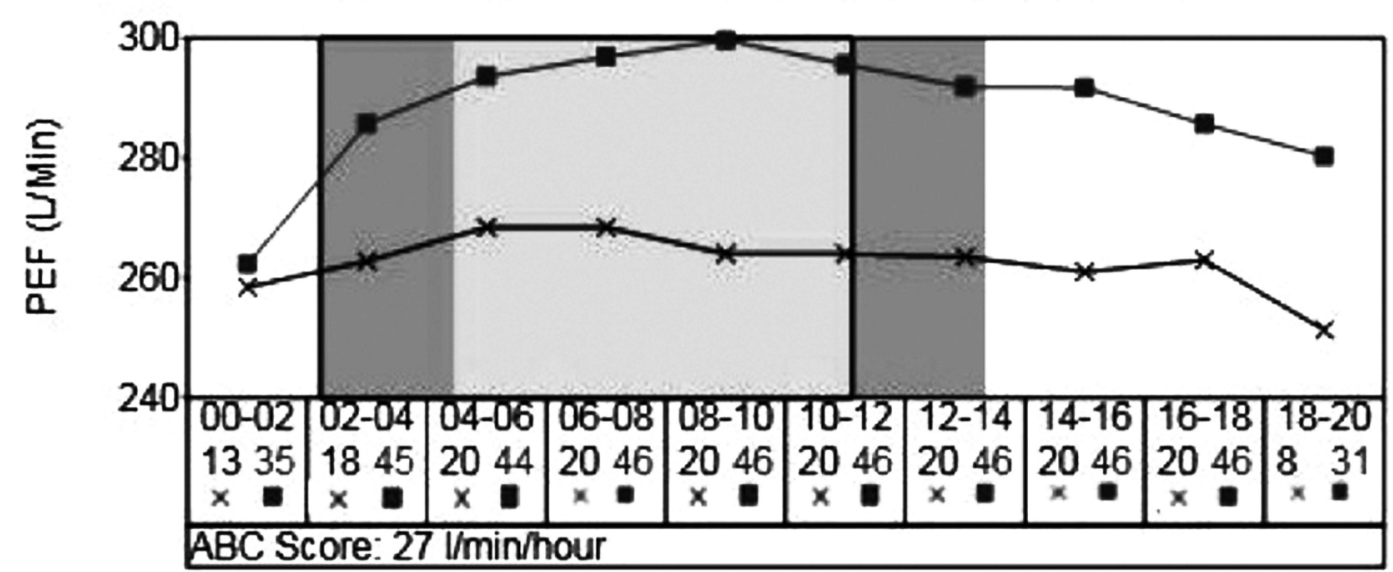

Hours From Waking, Number of Readings

(Day Shifts $\times$ ) (Rest $\bullet$ )

Figure 1 - (a): Shows the average PEF value for the same time of the day, for rest days ( $\square$ ) and for day shift days (x). The table includes the time intervals, in 2 hour quanta, starting with the 00:30 AM to 02.30 AM interval, and the number of readings used for the average (to the left, the number of readings for the day shift days, marked $x$ underneath, and to the right the rest days, marked $\mathbf{m}$ underneath. (b): Shows the average PEF value for the same time since waking, for rest days ( $\square$ ) and for day shift days (x). The table includes the time intervals, in 2 hour quanta, starting with the first 2 hours after waking, and the number of readings used for the average (to the left, the number of readings for the day shift days, marked $x$ underneath, and to the right the rest days, marked $\square$ underneath. Both graphs show a clear decrease of the average PEF values on day shift days compared with the rest days

because there is a need to confirm the relationship between the professional activity and the disease onset. In allergic asthma, the specific challenge test confirms without any doubt the occupational diagnosis, if the allergen is well selected. However, in many occupational diseases, etiology is multifactorial and this selection is difficult to do and might be wrong. The specific bronchoconstriction test needs special equipment and precautions and even so, involves a certain risk.

Repeated measurement of the peak expiratory flow (PEF) and comparing results of the measurement during and outside workplace environment exposure, represents an alternative method for the specific challenging test, included currently in all international guidelines to confirm the relationship between 
bronchial obstruction and the trigger factors of the asthma attack. The level of bronchial obstruction is explored by maximal flow during the first second of expiration (FEF1) and PEF. PEF has a lower sensitivity compared to FEF1, as it is only an instantaneous flow but has the advantage of being recorded directly by the instructed patient, at home or at work (9). The variability of bronchial obstruction is the key element of asthma and its correlation with exposure confirms the occupational diagnosis. The sensitivity and specificity of this method increase if there is a computer data interpretation, reaching $75 \%$ and, $98 \%$, respectively (10). In order to decide for this monitoring, anamnesis is the key element: the occurrence of the symptoms during the working time and the diminishing or even disappearance during holidays is a grade 2 level of evidence characteristics (11) for the positive diagnostic.

The occupational asthma diagnostic is supported in our case on the following typical elements of this adult onset asthma: clinical picture (start of symptoms after workplace air exposure and amelioration after changing the workplace), PEF monitoring during working period and vacation, and the epidemiological criteria: presence of respiratory symptoms in coworkers. PEF is an objective measurement validating the presence of bronchial obstruction in relation with the workplace exposure; therefore, it is the necessary element to confirm the occupational diagnosis. In different countries, monitoring PEF for occupational asthma diagnosis has different levels of utilization; in the United Kingdom, $66 \%$ of occupational asthma cases are diagnosed with this method, while in France only $31 \%$ are. $(12,13)$ The case we present is, for sure, not the only occupational asthma diagnosed by this method, but it is the first to be reported in extenso illustrating a case that couldn't be otherwise validated as occupational. Another specificity of this case is that this is asthma in a person that has not been exposed to hazards related to the technological process. Occupational asthma is defined as a disease caused by any risk factor present in the workplace (including atmospheric pollutants that might be present in the home environment such as fungus, mites, etc.). This is the case in our patient. Frequently, this is ignored by the treating doctor and also by the patient who doesn't make the link between the indoor exposure and his symptoms. An increasing number of occupational asthma cases have been reported in the last years linked to pollution of the air in different workplaces, in parallel with the increase of the number of people employed in service activities and with a better risk control of the industrial environment. $(14,15)$ There are more than 350 substances with asthmogenic risk in workplaces. (16) Reduction of their utilization and of their concentration in the air diminishes the risk of asthma development and also the risk of aggravation of a pre-existing asthma, significantly improving the quality of life for these patients. (16) With progressive modernization of the society, new domains of activity are created and new risk factors for asthma may appear in these workplaces.

The diagnosis of occupational asthma needs an investigation of the workplace, complete registration of the respiratory cases in that specific workplace, changing the working condition (whenever possible) or changing the workplace for those who have already developed symptoms. Without cessation of the occupational exposure, the clinical evolution of the asthma is impossible to control, even with all guidelines recommendations are completely followed.

\section{CONCLUSION}

Each case of bronchial asthma with adult onset needs a careful and complete occupational anamnesis, no matter of the workplace the person is performing his activity and a PEF monitoring during exposure and during holidays. PEF monitoring represents the method of validation of the occupational diagnosis. Ameliorating the air quality in workplaces improves life quality of all patients with bronchial asthma and should be one of the priorities of the occupational physician in charge with the medical surveillance of the employees, including those with office based activity.

\section{REFERENCES}

1. Global Burden of Disease Study 2013 Collaborators. Global, regional, and national incidence, prevalence, and years lived with disability for 301 acute and chronic diseases and injuries in 188 countries, 1990-2013: a systematic analysis for the Global Burden of Disease Study 2013. Lancet. 2015 Aug 22;386(9995):743-800.

2. White GE, Mazurek JM, Storey E. Employed adults with asthma who have frequent workplace exposures. J Asthma. 2015 Feb;52(1):46-51.

3. Rascu A. Epidemiologie in ASTMUL BRONSIC PROFESIONAL - Note de curs pentru studenti si rezidenti. Bucuresti: Editura Universitara; 2006.

4. Chan-Yeung M1, Malo JL. Occupational asthma. N Engl J Med. 1995 Jul 13;333(2):107-12.

5. Occupational Respiratory Diseases_Australia_2006_ArchivePDF.pdf Occupational Respiratory Diseases in Australia, http://www.safeworkaustralia.gov.au/sites/SWA/about/Publications/Documents/114/.

6. Bessot JC, Pauli. Avant propos in L'asthme professionnel, 1999, VII.

7. Kogevinas M, Antó JM, Sunyer J, Tobias A, Kromhout H, Burney P, et al. Occupational asthma in Europe and other industrialised areas: a population-based study. European Community Respiratory Health Survey Study Group. Lancet. 1999 May 22;353(9166):1750-4.

8. Lim T, Liss GM, Vernich L, Buyantseva L, Tarlo SM. Work-exacerbated asthma in a workers' compensation population, Occup Med (Lond). 2014 Apr;64(3):206-10. 
9. Hargreave FE, Ramsdale EH, Pugsley SO. Occupational asthma without bronchial hyperresponsiveness. Am Rev Respir Dis. 1984 Sep; 130(3):513-5.

10. Gannon PF, Newton DT, Belcher J, Pantin CF, Burge PS. Development of OASYS-2: a system for the analysis of serial measurement of peak expiratory flow in workers with suspected occupational asthma. Thorax. 1996 May;51(5):484-9.

11. Kopferschmitt-Kubler MC, Popin E, Pauli G. The diagnosis and management of occupational asthma Rev Mal Respir. 2008 Oct;25(8): 999-1012. French

12. Bakerly ND, Moore VC, Vellore AD, Jaakkola MS, Robertson AS, Burge PS. Fifteen-year trends in occupational asthma: data from the Shield surveillance scheme. Occup Med (Lond). 2008 May; 58(3):169-74.

13. Ameille J, Pauli G, Calastreng-Crinquand A, Vervloët $D$, Iwatsubo $Y$, Popin $E$, et al. Reported incidence of occupational asthma in France,
1996-99: the ONAP programme. Occup Environ Med. 2003 Feb; 60(2):136-41.

14. Anderson NJ, Fan ZJ, Reeb-Whitaker C, Bonauto DK, Rauser E. Distribution of asthma by occupation: Washington State Behavioral Risk Factor Surveillance System Data, 2006-2009. J Asthma. 2014 Dec;51(10):1035-42.

15. Wortong $D$, Chaiear N, Boonsawat W. Risk of asthma in relation to occupation: A hospital- based case-control study. Asian Pac J Allergy Immunol. 2015 Jun;33(2):152-60.

16. Torén K, Blanc PD. Asthma caused by occupational exposures is common - a systematic analysis of estimates of the populationattributable fraction. BMC Pulm Med. 2009 Jan 29;9:7.

17. Le Moual N, Carsin AE, Siroux V, Radon K, Norback D, Torén K, et al. Occupational exposures and uncontrolled adult-onset asthma in the European Community Respiratory Health Survey II. Eur Respir J. 2014 Feb;43(2):374-86. 